\title{
Clinical rehabilitation research advances in spinal cord injury
}

\author{
J A DeLisa MD
}

Immediate Past President American Paraplegia Society, Department of Physical Medicine and Rehabilitation, New Jersey Medical School, University Hospital, Newark, NJ 07103 USA.

President Bush and Congress have designated the 1990s 'The Decade of the Brain', emphasizing potential breakthroughs in the prevention, treatment and rehabilitation of many central nervous system (CNS) disorders including CNS injury.

The spinal cord is a unique window to the CNS. Activity-dependent synaptogenesis, competitive synaptogenesis, reactive synaptogenesis, neuromodulation, axoplasmic transport, and electrical stimulation effects are currently being studied, and may have major implications for the treatment and management of SCI patients. ${ }^{1}$

As clinicians we need to encourage and foster collaborative ties with basic scientists to enhance recovery and maximize function and independence, as well as to reduce secondary complications for our patients. This is an exciting era; the advances in neurotransmitter chemistry, neuropharmacology, biochemistry, physiology, molecular biology, computer modeling, and biomedical engineering will have a major impact on the management of spinal cord injury patients.

It is difficult to highlight and do justice to the exciting advances in clinical research with respect to treatments, improved equipment and assistive devices. Multicenter clinical trials to minimize secondary neurological injury after acute spinal cord trauma are underway. Several pharmacological interventions, such as high dose methylprednisolone and GM-l ganglioside, have shown some promise in reducing the long term effects of such trauma.,3 However, the mechanisms of action of these drugs are still unknown. Other pharmacological agents have also shown promise for use in spinal cord injury and are being studied. ${ }^{4,5}$

Intrathecal catheters and pumps allow for the administration of neuroactive and pos- sibly neurotrophic agents directly onto the spinal cord for treatment of spasticity and pain. Electrodiagnosis is being used to predict recovery. ${ }^{6}$ Evaluation for progressive syringomyelia, conduction of descending motor pathways, and mapping the motor cortex after spinal cord injury are possible using electromagnetic cortical stimulators. ${ }^{7}$

Renal failure is no longer a leading cause of death in SCI patients. Careful monitoring using renal scans and/or renal ultrasound, urodynamic tests, and lithotripsy have improved outcomes for these patients. The same detail and clinical research is needed with respect to monitoring the respiratory system. Similar emphasis and clinical trials using a low dosage of heparin, external pneumatic compression, and/or electrical stimulation have markedly decreased the incidence of deep vein thrombosis, pulmonary embolism, and death in acute SCI patients. ${ }^{8,9}$

Rehabilitation engineering has made substantial advancements in computer technology, metallurgy and development of new materials. These advances have produced lighter weight, stronger wheelchairs; a onehanded joystick control drive cam; voice controlled wheelchairs; and environmental control systems. Functional neuromuscular stimulation (FNS) has been used to create upper extremity function in quadriplegics and has enabled complete and incomplete paraplegics to ambulate. The computerized closed loop bicycle ergometer has been shown to elicit significant increases in aerobic metabolism, pulmonary ventilation, and cardiac volume loading above resting and passive exercise levels. ${ }^{10}$

Male infertility, most often caused by ejaculation dysfunction and poor semen quality, often follows SCI. However, improved technology for sperm collection and 
processing, and for artificial insemination, has allowed SCI males to father children. ${ }^{11}$ Female sexuality and dysfunction after SCI has not been widely studied. The studies which have been completed have focused primarily on menstruation and pregnancy. ${ }^{12}$

Issues associated with the aging spinal cord injured patient have not been widely studied. These issues include overuse syndromes, loss of support systems, and the aging process, all of which present significant challenges to these patients and the health care team. This area should be a major target for research in the coming decade.

The journal of the American Paraplegia Society disseminates new information to improve the quality of care given to those who experience spinal cord paralysis and provides a milieu in which to exchange ideas and to encourage future research.

The American Paraplegia Society (APS) is dedicated to improving the quality of care provided to spinal cord injured individuals. The Society is organized to function exclusively for scientific and educational purposes.

\section{References}

1 Little JW (1990) The decade of the spinal cord. (Editorial). J Am Paraplegia Soc 13: 32.

2 Bracken M, Shepard MJ, Collins WF, Holford TR, Young W, et al (1990) A randomized, controlled trial of methylprednisolone or naloxone in the treatment of acute spinal cord injury: results of the second national acute spinal cord injury study. $N E$ J Med 322: 1405-1411.

3 Geisler FH, Dorsey FC, Coleman WP (1991) Recovery of motor function after spinal-cord injury: a randomized, placebo-controlled trial with GM-1 ganglioside. $N$ E J Med 324: 1829-1838.

4 Bernton E (1985) Naloxone and TRH in the treatment of shock and trauma: what future roles? Ann Emerg Med 14: 729-723.

5 Hall ED (1987) Beneficial effects of the 21-amniosteroid U74006F in acute CNS trauma and hypovolemic shock. Acta Anaesth (Belgium) 38: 421-425.

6 DeLisa JA, Little JW (1990) Electrodiagnosis and recovery of function. Am J Phys Med Rehabil 67: 44-49.

7 Robinson LR, Little JW (1990) Motor-evoked potentials reflect spinal cord function in post-traumatic syringomyelia. Am J Phys Med Rehabil 69: 307-310.

8 Merli GJ, Herbison GJ, Ditunno JF, et al (1988) Deep-vein thrombosis: prophylaxis in acute spinal cord injured patients. Arch Phys Med Rehabil 69: 661-664.

9 Merli GJ, Rensman B, Doyle L, et al (1990) Prophylaxis for deep-vein thrombosis in acute spinal cord injury comparing two doses of low molecular weight heparinoid (ORG 10172) in combination with either external pneumatic compression or electrical stimulation. American Spinal Injury Association Abstracts Digest 16th annual scientific meeting: 8 .

10 Sipski ML, DeLisa JA (1991) Functional electrical stimulation in spinal cord rehabilitation: a review of the literature. Neuro Rehabil 1 (4): 46-57.

11 Linsenmeyer TA, Perkash I (1991) Infertility in men with spinal cord injury. Arch Phys Med Rehabil 72: 747-754.

12 Sipski ML (1991) The impact of spinal cord injury on female sexuality, menstruation and pregnancy: a review of the literature. $J$ Am Paraplegia Soc 14: 122-126. 